\title{
Noelle Benhamou, Valérie Gramfort, Quand le jeune Zola monte un canular...
}

Isabella Giovinazzo

\section{(2) OpenEdition}

\section{Journals}

\section{Edizione digitale}

URL: https://journals.openedition.org/studifrancesi/38162

DOI: 10.4000/studifrancesi.38162

ISSN: 2421-5856

Editore

Rosenberg \& Sellier

\section{Edizione cartacea}

Data di pubblicazione: 15 décembre 2004

Paginazione: 641-642

ISSN: 0039-2944

\section{Notizia bibliografica digitale}

Isabella Giovinazzo, «Noelle Benhamou, Valérie Gramfort, Quand le jeune Zola monte un canular...», Studi Francesi [Online], 144 (XLVIII | III) | 2004, online dal 30 novembre 2015, consultato il 08 mai 2021. URL: http://journals.openedition.org/studifrancesi/38162 ; DOI: https://doi.org/10.4000/studifrancesi. 38162

Questo documento è stato generato automaticamente il 8 mai 2021

\section{(c) $($ ) $\odot$ (8)}

Studi Francesi è distribuita con Licenza Creative Commons Attribuzione - Non commerciale - Non opere derivate 4.0 Internazionale. 


\title{
Noelle Benhamou, Valérie Gramfort, Quand le jeune Zola monte un canular...
}

\author{
Isabella Giovinazzo
}

\section{NOTIZIA}

NOELLE BENHAMOU, VALÉRIE GRAMFORT, Quand le jeune Zola monte un canular..., «Romantisme» n. 116 (II trim, 2002) pp. 65-73.

1 L'articolo è dedicato ad un esempio di mistificazione letteraria messo in opera da Zola, che in occasione della pubblicazione delle opere complete di Baudelaire nel 1869, diffonde dei presunti inediti del poeta, i quali vengono però immediatamente individuati come falsi. Alla base di questo episodio sono evidenti da un lato la volontà di Zola di screditare Baudelaire e in genere la poesia, a vantaggio del romanzo e del naturalismo, dall'altro la volontà di lanciare l'amico Paul Alexis, autore dei testi, che in realtà otterrà da tale episodio la fama costante di plagiario, anche a dispetto della scarsa eco effettivamente avuta dalla questione. In appendice, sono presentati alcuni dei componimenti poetici di Alexis accompagnati dalle note introduttive di Magnard, in occasione della pubblicazione, Roux e Levy. 